Check for updates

Bogotá, Colombia

lukestephentaylor@gmail.com Cite this as: BMJ2021;372:n394 http://dx.doi.org/10.1136/bmj.n394 Published: 12 February 2021

\section{Covid-19: Is Manaus the final nail in the coffin for natural herd immunity?} Many thought a second wave was impossible in Brazil's Amazon because of the severity of the first.
A second crisis has stunned the city of Manaus, reports Luke Taylor, and raises questions around a
new variant and the likelihood of natural herd immunity

\section{Luke Taylor freelance journalist}

Hospitals in the Brazilian Amazon collapsed for the second time in mid-January.

A surge in patients with covid-19 exhausted hospital supplies of oxygen in the region's capital of Manaus, forcing friends and families of patients to race to private suppliers. Queuing for hours in the heat and torrential downpours, they are desperate to buy a $\$ 70$ ( $£_{51} ; €_{58}$ ) cylinder that could turn out to be a lifesaver. Some patients are being airlifted to other states where beds are available. But, again, capacity is limited, so many in Manaus-where the crisis extends well beyond the hospital walls-are dying of asphyxiation.

"A lot of people have died at the hospital entrance and outside in the ambulance, but most have died and are still dying at home while their families search the city for oxygen," says Jesem Orellana, a public health researcher at Brazil's Oswaldo Cruz Foundation.

Around 80 confirmed covid-19 deaths were reported each day in May 2020-Manaus was the first Brazilian city to dig mass graves. In the second wave in January 2021 that number exceeded 100. The new heights of despair in a city that suffered so much with the first wave came as a shock to residents and public health experts alike.

It has alarmed researchers across the world too. Many thought a second wave impossible because of the scale of the previous outbreak. "The academic community thought they were close to herd immunity," says Diego Rosselli, an epidemiologist at Bogotá's La Javeriana University. “Once again, we had it wrong."

To top it all, a new variant of the virus, P.1, has been detected in Manaus. Like other recently detected variants, it seems to be more infective and may escape antibodies that previously provided protection against SARS-CoV-2.

The riverside city, home to two million people and a hub for the myriad indigenous communities who live in the vicinity, is now the epicentre of Brazil's epidemic, a country already suffering the second highest number of deaths in the world.

\section{Unherd}

The initial title of a non-peer reviewed study released in pre-print in September 2020, Covid-19 herd immunity in the Brazilian Amazon, was, in hindsight, premature. ${ }^{1}$ Why the conclusion was so wrong is less certain, and not just down to overly optimistic assumptions.

For one thing, using blood donors as a sample may have skewed the results. "Donors are a special subset of the population," says Paulo Lotufo, an epidemiologist at the University of São Paulo. They are more likely to spend time outside the home and work in jobs that put them at higher risk of contracting covid-19, he says. Lotufo believes the proportion of residents who have antibodies was likely lower, and that false confidence created by the first study played a role in causing the second surge in cases.

But several leading epidemiologists, while acknowledging the study's limitations, believe significant inaccuracies are unlikely.

"It's possible that the modelling is wrong, and seroprevalence (the amount of antibodies measured in the blood serum as a marker of pathogen exposure, used to estimate the proportion of the population that has been infected) in people is actually lower, " says William Hanage, an epidemiologist at Harvard. "But I don't think it's possible that they were that much lower."

Applying the expected fatality rate of covid-19 in Manaus with the study's estimated $76 \%$ seroprevalence rate would also result in around the same amount of deaths that have been reported there, Hanage and others point out. "It's likely that a large proportion of the population has been infected," concludes Deepti Gurdasani, an epidemiologist at Queen Mary University of London.

The donors mirror the general population well in age and income, contends Nuno Faria, an Oxford epidemiologist who co-led the study. "Excluding samples from people with covid-19 symptoms may have actually resulted in an undercount of antibodies," he says.

So if the majority of the population had already been infected, and antibody levels really were that prevalent, how could the levels of infection have shot back up?

\section{New strain, new fears}

There are three explanations for how the virus could be spreading quickly despite most of the population having been infected, say experts.

One is that people are being reinfected by the coronavirus as antibodies gradually decline 
post-infection. That tendency is central to the John Snow Memorandum signed by 7000 experts and healthcare workers last year in opposition to those who called for a "natural herd immunity" strategy, which would have allowed the virus to spread through the population to provide exposure.

But that theory seems "unlikely" in this case, Hanage says. "There have been reasonably good studies from elsewhere which have suggested that immunity tends to last at least eight months.” Cases in Manaus peaked in May.

More compelling, and more concerning, is that the situation could be explained by the variant, P.1.

Like the B.1.351 variant detected in South Africa and B.1.1.7 first found in the UK, P.1 has evolved quicker than expected. And just like B.1.351 most of its mutations are on the site of the spike protein which binds to and penetrates human cells.

"While some of these mutations are known to have impacts upon immunity, we don't know what they are doing in combination," Hanage says. "And it's in this place where there is something circulating, which looks suspect, that we are seeing a large number of hospitalisations and deaths. That's a large part of why we are looking at Manaus with such sweaty palms."

P.1 could be more transmissible-among its mutations is one called N501Y, which is also in B.1.1.7 and has been linked to increased infectivity in mouse models, ${ }^{2}$ which would push the herd immunity threshold higher.

But it could also have evolved to evade antibodies from previous strains. The first confirmed reinfection involving P.1. was reported in Manaus on 18 January. ${ }^{3}$ Early studies examining how antibodies fight the new variants suggest that a mutation known as E484K, present in both P.1 and the South African variant, could be helping the virus evade antibodies and reinfect people. ${ }^{4}$

Though how P.1 could be driving the surge in cases in Manaus is uncertain, Hanage suspects it is playing a role. As well as the recent cases of reinfection, analysis shows that P.1 has become the dominant strain in Manaus, increasing the likelihood it is causing the current crisis.

\section{Lessons to be learnt}

Further studies are needed to understand P.1's role. There are already, however, lessons to be learnt.

Mobility data in Manaus shows a gradual increase in people going out to socialise, shop, and work after the first wave of cases. Activity peaked at Christmas shortly before hospitals buckled. Careless behaviour from the local community, which did not appear to adhere to social distancing, and insufficient action from the state governor, have been blamed.

Both have been attributed to misplaced confidence that the region had become immune to covid-19-supported by that preliminary study. "There was a sensation that the pandemic was over. You had had a bad time, but now you were free to do anything you wanted," Lotufo says.

State authorities ordered shops to close for 15 days on 26 December when cases were climbing, only to reverse the decision following street protests from local businesses and workers.

Other vulnerable communities in the Amazon, such as in Iquitos, Peru, where studies estimate similarly high levels of antibodies (70\%), could find themselves in the same position. ${ }^{5}$ Manaus has illustrated both the uncertainties and dangers of letting the virus spread unmitigated, as some propose.

"Manaus shows that pursuing herd immunity through natural infection is not a guarantee. And second, even if we could reach it, hundreds of thousands of people will die in pursuit," Gurdasani says. The more the virus spreads the more likely it is to mutate, too.

Back on the ground, the situation is still dire. Venezuela, itself suffering a pandemic crisis, ${ }^{6}$ donated supplies of oxygen to ease the shortage, and Brazil's air force has been airlifting supplies to the riverside city, but it has not been enough to plug the gap.

The city is able to produce only a third of the oxygen needed, say Médecins Sans Frontières, ${ }^{7}$ who warn of the knock-on effect on towns upriver of the capital, in the rural Amazon region. With a lack of healthcare infrastructure and an immunologically naive population, the effects of misplaced optimism and a rampant new strain could be even more devastating.

Commissioned, not peer reviewed.

Competing interests: I have read and understood BMJ policy on declaration of interests and have no relevant interests to declare.

1 Buss LF, Prete CA, JrAbrahim CMM, et al. Covid-19 herd immunity in the Brazilian Amazon.medRxiv 2020.09.16.20194787 [Preprint]. www.medrxiv.org/content/10.1101/2020.09.16.20194787v1doi: 10.1101/2020.09.16.20194787.

2 Rambaut A, Loman N, Pybus O, et al. Preliminary genomic characterisation of an emergent SARS-CoV-2 lineage in the UK defined by a novel set of spike mutations. December 2020. https://virological.org/t/preliminary-genomic-characterisation-of-an-emergent-sars-cov-2-lineagein-the-uk-defined-by-a-novel-set-of-spike-mutations/563.

3 Naveca F, Da Costa C, Nascimento V, et al. SARS-CoV-2 reinfection by the new Variant of Concern (VOC) P.1 in Amazonas, Brazil. January 2021. https://virological.org/t/sars-cov-2-reinfection-bythe-new-variant-of-concern-voc-p-1-in-amazonas-brazil/596.

4 Le Page M. Can coronavirus variants reinfect people and evade the vaccines? New Scientist2021. www.newscientist.com/article/2265221-can-coronavirus-variants-reinfect-people-and-evadethe-vaccines.

5 Álvarez-Antonio C, Meza-Sánchez G, Calampa C, et al. Seroprevalence of anti-SARS-CoV-2 antibodies in Iquitos, Loreto, Peru.medRxiv2021.01.17.21249913 [Preprint]. 2021. www.medrxiv.org/content/10.1101/2021.01.17.21249913v1.

6 Taylor L. Covid-19: Venezuela's doctors refuse to be gagged. BMJ2020;371:m3938 doi: 10.1136/bmj.m3938 pmid: 33077420

7 Coronavirus covid-19 collapses health system in Manaus, Brazil. MSF 21 January 2020. www.msf.org/coronavirus-covid-19-collapses-health-system-manaus-brazil.

This article is made freely available for use in accordance with BMJ's website terms and conditions for the duration of the covid-19 pandemic or until otherwise determined by BMJ. You may use, download and print the article for any lawful, non-commercial purpose (including text and data mining) provided that all copyright notices and trade marks are retained. 